\title{
Optimal Procurement Mechanisms: \\ Bidding on Price and Damages for Breach
}

\author{
Ottorino Chillemi* and Claudio Mezzetti **
}

February 18, 2013

\begin{abstract}
We study the optimal procurement mechanism when contract breach and abandoning a project may be efficient, either because of completion costs higher than anticipated, or new and more lucrative opportunities for the contractor. When contractors have private information about their costs, the procurer finds it optimal to set damages above expectation damages. There is a lock-in effect, or status-quo bias; the agent that has won the award will complete the project even in situations when it would be efficient to abandon it. If the cost types of all agents are above a threshold, the optimal bidding procedure assigns the project by lottery. The optimal mechanism cannot be implemented by standard auction formats. However, the larger the number of agents bidding for the project, the closer auctions with a liquidated damage clause approximate the optimal mechanism.
\end{abstract}

KEYWORDS: Procurement, principal-agent, contract breach, liquidated damages.

JEL Classification Numbers: D44, D82, H57, L51.

* Department of Economics, University of Padua, Italy.

** Department of Economics, University of Melbourne, VIC, Australia. (Corresponding author: cmez@unimelb.edu.au) 


\section{Introduction}

Procurement is an important component of economic activity. According to the World Trade Organization, government procurement alone accounts for 10-15 percent of GDP. ${ }^{1}$ Many procurement projects require the procurer to sink specialized resources once the contractor has been selected and execution has begun. In such cases, non performance, or contract breach, is an important concern; replacing the contractor may be difficult. The construction industry is a particularly good example. Because most of the work is subcontracted and firms often are small, it is relatively easy to shut down and then open a new business under a different name; contract breach is not very costly for contractors, but it can be disruptive for procurers. ${ }^{2}$

Competitive bidding is often used to select the agent in charge of completing a project. Once the winning agent has been selected, he enters in a contractual relationship with the principal. It is often the case that before the project starts the principal and the winning agent do not know all the details surrounding the project. It may well turn out, for example, that executing the project is more costly than anticipated. In addition, new and more lucrative opportunities may arise for the agent. In some instances, completion costs may turn out to be so high, or a new alternative opportunity so lucrative, that it would be efficient to abandon the project.

Matters are complicated by the fact that the agent normally has private information about his productivity and is the one who discovers the true value of the completion cost and of his outside option. The agent always has an incentive to overstate his cost and the value of the outside option. Cost overstating could be addressed by using fixed price contracts, but, apart from asking the agent to bear all the risk, fixed price contracts have the drawback of providing the agent with an incentive to breach the contract without completing the project even when completion is efficient.

Procurers are aware of the risk of contractor breach, and have put in place several contractual arrangements to ameliorate the problem. Stipulated damage payments for breach of contract, known as liquidated damage clauses, are the most commonly used arrangement. ${ }^{3}$ However, in common law countries the courts have imposed con-

\footnotetext{
${ }^{1}$ See http://www.wto.org/english/tratop_e/gproc_e/gproc_e.htm

${ }^{2}$ According to construction management professionals, a large number of USA construction firms stay in business for a short time. For example, Ganaway (2006) claims that only 43 per cent of U.S. construction firms remain in business after four years. The situation is not much different in other countries.

${ }^{3}$ Performance bonds and third party guarantees like letters of credit and surety bonds are also
} 
straints on these contractual arrangements. Liquidated damage clauses that exceed expectation damages are typically invalidated by the courts (e.g., see Uniform Commercial Code, $\S \S 2-302(1), 2-718(1)$, and the Restatements of Contract (Second) $\S \S$ 208, 356. $)^{4,5}$

Another approach that is used to address the contract default problem is to adopt bidding formats specifically designed to minimize default. One common feature of these bidding formats is to rule out bids that are perceived as excessively low. Winners that bid low, it is argued, have a bigger incentive not to perform the contractual task. For instance, the directory 2004/18/EC of the European Union for public works prescribes that "abnormally low tenders" can win the auction only if reliability is assessed in an audit conducted by the procurer. ${ }^{6}$

In this paper, we adopt a mechanism design approach to study the optimal contract and bidding procedure in situations where contract breach and abandoning a project may, or may not, be socially efficient. We are interested in understanding what contractual arrangements are optimal and whether the current legal and regulatory practice of limiting damages in contract law is justified. We are also interested in uncovering the distortions introduced by the fact that the opportunity cost of completion is only discovered by the agent, who also has private information about his productivity.

We show that if there were common knowledge about the agents' productivities, the principal would set liquidated damages equal to expectation damages and choose an up-front payment to the project winner that extracts all the surplus. The agent would make the efficient completion decision, abandoning the project when social cost exceeds social value.

With private information about the agents' costs, the optimal contract depends

used.

${ }^{4}$ Expectation damages is the legal term for the ex-ante expected loss to the principal.

${ }^{5}$ In most civil law countries, penalty clauses are enforceable, but they may be mitigated by the courts

${ }^{6}$ Procedures that exclude bids automatically have been recently opposed by the EU Commission, because of their anticompetitive flavor, and now they can be used in the EU only for awarding contracts of limited amount (e.g., up to 1 million euros in the case of Italy) - this exemption is explicitly justified by the high costs of testing bidder reliability in the case of small projects. The many shortcomings of bidding procedures that exclude abnormally low tenders have been studied by Albano et al. (2006) and Decarolis (2011). Recent studies of alternative procurement procedures include Postl (2012) and Rezende (2009). 
on the value of the project to the principal. If the project is of high value, then the principal will make sure that the project is always completed, as social efficiency would dictate. This can be done by offering the same contract as under complete information, with liquidated damages equal to expectation damages and no information rent for the agent. On the contrary, if the value of the project is such that it is sometimes efficient to abandon it, then the winning agent's informational advantage has bite and he is able to extract information rents.

Importantly, in order to reduce the agent's information rent the principal will find it optimal to write a punitive damage clause in the contract (i.e., to set damages above expectation damages). As a result, a feature of the optimal contract is a lock-in effect, or status-quo bias; the agent that has won the award will complete the project even in situations when it would be efficient to abandon it. The agent may pass up outside opportunities of higher social value and complete the project instead, in order to avoid paying punitive damages. This is the first distortion due to incomplete information.

A feature of the optimal bidding procedure under both complete and incomplete information is that if the cost types of all agents are above a threshold, then the project is assigned by lottery. Indeed, when the procurer uses a lottery to assign the project, it makes sure that the payment to the winning agent and the liquidated damage clause are such that the project is always completed. When a lottery is used, the agent obtains no information rent even under incomplete information. To reduce the agent's information rent, the second distortion the principal introduces in the optimal mechanism under incomplete information is to award the project by lottery more frequently than under complete information. ${ }^{7}$

An additional conclusion of our analysis is that the optimal mechanism cannot be implemented by standard auction formats, not even if we add a liquidated damage clause to the agents' bids. This is because in an optimal mechanism the liquidated

\footnotetext{
${ }^{7}$ In public procurement, awarding projects by lottery is not unheard of. As an example consider the auction to build a police station in the Sicilian municipality of Palma di Montechiaro. The auction rules required to eliminated the $10 \%$ highest and the $40 \%$ lowest reductions over the base price, and then to pick as winner the bid closest to the average of the remaining bids. There were exactly 24 bids closest to the average and the actual winner was determined by a lottery draw. Our paper uncovers settings were lotteries might be optimal, but it is well known that they are highly inefficient in many circumstances (e.g., see Milgrom, 2004); we do not advocate their generalized use as allocation mechanisms. We refer again to Albano et al. (2006) and Decarolis (2011) for a discussion of the shortcomings of bidding procedures that exclude abnormally low tenders.
} 
damage clause depends on the agent's cost type, which is private information. However, the smaller the variability in cost types across agents and the larger the number of agents bidding for the project, the closer auctions with a liquidated damage clause approximate the optimal mechanism.

One policy implication of our model is that when the courts invalidate punitive contractual damages, they may be enhancing the social efficiency of contracts, but they also redistribute surplus from the principal to the contractor. Thus, our paper shows that invalidation of punitive contractual damages may be justified if the courts' overriding goal is to promote efficiency, in the sense of maximizing total surplus. At the same time, in public procurement it may be reasonable to attach a higher welfare weight to the procurer's payoff than the contractor's profit; if this is so, then liquidated damages higher than expectation damages ought to be enforced and current court practice is not justified.

Thus, it is difficult to understand why the rule that liquidated damages cannot exceed expectation damages should have general validity, irrespective of the circumstances. Edlin and Schwartz (2003) review the literature on contractual damage clauses and reach a similar policy conclusion. The literature has shown that penalties - damages that exceed expectation damages - may be welfare enhancing (e.g., when parties must make relation specific investments as in Edlin and Reichelstein, 1996) or welfare reducing (e.g., when parties use a punitive damage clause to deter entry, as in Chung, 1992). The paper closer to us is Stole (1992). He shows that when a seller is trying to screen buyers whose valuations are private information, the optimal mechanism requires liquidated damages below expectation damages. Our story is also based on incomplete information, but we reach the opposite conclusion, the procurer's optimal contract requires penalties - a liquidated damage clause above expectation damages.

Our paper is also related to the literature on default in auctions. Spulber (1990) was the first to note that auctions may provide incentives for contractors to default when there are cost overruns. His efficiency restoring solution is to introduce expectation damages. ${ }^{8}$ Waehrer (1995), on the other hand, requires the winning bidder to post a deposit that is lost in case of default. In Zheng (2001), a budget constrained winning bidder may borrow in order to pay above his budget, which is private infor-

\footnotetext{
${ }^{8}$ Ramchurn et al. (2009) show that by rewarding all bidders in case of success and penalizing them in case of failure, efficiency can be obtained even in the case of multidimensional private information.
} 
mation. Rhodes-Kropf and Viswanathan (2005) extend Zheng's analysis; their focus is on how different ways of financing bids affect bidding behavior. Zheng (2009) shows that, if implemented, the 2008 U.S. Treasury plan of auctioning toxic assets might have induced poor bidders to outbid rich bidders, and then to default on the government loans in case of unsalvageable assets. Parlane (2003), Board (2007), and Burguet et al. (2012) study procurement mechanisms with bidders that have limited liability. Wan and Beil (2009) allow the principal to test a bidder's risk of default both before and after bidding.

Finally, related is also the literature on auctions where the winner has the right to withdraw his bid. Von Ungern-Sternberg (1991) argues that such auctions are the norm in the Swiss construction industry. He studies a simultaneous sealed-bid multi-object procurement auction and shows that letting the winner have the right to withdraw his bid is beneficial to the principal, by leading to lower equilibrium prices when bidders face rising marginal costs. Asker (2000) considers a single-item auction in which bidders only discover after the auction whether the item is a "good" or a "bad". He shows that the right to withdraw the offer raises the seller's expected revenue and provides experimental evidence supporting the theory.

The paper proceeds as follows. Section 2 presents the model. Section 3 solves for the complete information benchmark, while Section 4 studies the optimal procurement mechanism under incomplete information. Section 5 looks at standard auctions, and Section 6 concludes.

\section{The Model}

There are $N$ risk-neutral agents, indexed by $i \in \mathcal{N}=\{1, \ldots, N\}$ and one principal. The principal has a project that can only be undertaken by one of the agents. Each agent also has an alternative project that he could pursue instead of working for the principal. Each agent $i$ has a private $\operatorname{cost} k_{i}$ of working on either project. The principal's and alternative project also have common cost components, $\gamma^{P}$ and $\gamma^{A}$ respectively, which we interpret as cost overruns. The agent's benefit from working on the principal's project is the compensation stipulated in the contract offered by the principal. We model the benefit from working on the alternative project as a random variable $\omega$. The cost components $\gamma^{P}, \gamma^{A}, k_{i}$ are also random variables. Benefit $\omega$ and $\operatorname{costs} \gamma^{P}, \gamma^{A}, k_{i}, i \in \mathcal{N}$, are independently distributed. 
Each agent $i$ has private information about the private cost type $k_{i}$; the types $k_{i}$ are drawn independently from the same distribution $G(k)$ which is absolutely continuous with support $K=\left[k^{-}, k^{+}\right]$and density $g(k)=G^{\prime}(k)$. We make the standard assumption that $G\left(k_{i}\right) / g\left(k_{i}\right)$ is an increasing function of $k_{i}$.

The agent that wins the principal's contract discovers the value of the cost overruns $\gamma^{P}$ during the project's completion, after having sunk the cost $k_{i}$ in it. At that point, the agent may abandon the principal's project and pursue the alternative opportunity which has an expected net payoff of $E[\omega]-E\left[\gamma^{A}\right]-k_{i}$, where $E[\omega]$ is the expected benefit and $E\left[\gamma^{A}\right]$ the expected cost overruns. We assume that $E[\omega]-E\left[\gamma^{A}\right] \geq k^{+}$, so that the outside option has non-negative value for all agents. We can think of the opportunity cost of continuing the principal's project as

$$
\gamma^{P}+\left(E[\omega]-E\left[\gamma^{A}\right]-k_{i}\right)
$$

Defining

$$
c=\gamma^{P}+E[\omega]-E\left[\gamma^{A}\right],
$$

we can write the opportunity cost of completing the principal's project as $c-k_{i}$. It is then convenient to view the cost $c$ as being drawn from a distribution $F(c)$, which is absolutely continuous with support $\left[c^{-}, c^{+}\right]$and density $f(c)=F^{\prime}(c)$.

We want to study the contract design problem of the principal under the constraint that the contract may specify damage payments for breach, but the agent must remain free to quit the relationship. We adopt a mechanism design approach. By the revelation principle, there is no loss of generality in considering only direct mechanisms in which the principal chooses the probability of assigning the project and the penalties and bonuses for each agent, as functions of the agents' reported cost types and project completion. Denote by $K_{-i}=\left[k^{-}, k^{+}\right]^{N-1}$ the set of types of agent $i$ 's opponents with generic element $k_{-i}$ and let $g_{-i}\left(k_{-i}\right)=\Pi_{j \in I, j \neq i} g\left(k_{j}\right)$ be the associated density function. We denote by $\pi_{i}\left(k_{i}, k_{-i}\right)$ the probability that the project is assigned to agent $i$. Let $t_{i}^{L}\left(k_{i}, k_{-i}\right)$ be the fee charged to agent $i$ when he participates in the mechanism but does not win the project; let $t_{i}^{F}\left(k_{i}, k_{-i}\right)$ be the amount charged to $i$ when he wins the project but breaches the agreement to complete it; let $\beta_{i}\left(k_{i}, k_{-i}\right)$ be the bonus paid to winner $i$ if he completes the project. ${ }^{9}$ Note that the principal would not benefit from conditioning the transfers $t_{i}^{F}$ and $\beta_{i}$

\footnotetext{
${ }^{9}$ As will become clear later, in the optimal contract the participation fee $t_{i}^{L}$ could be set to be equal to zero for all cost types; charging the losing agents is not necessary.
} 
on a cost report by the agent once the agent has discovered the cost $\gamma^{P}$. Incentive compatibility implies that $t_{i}^{F}$ and $\beta_{i}$ cannot vary with $\gamma^{P}$.

After discovering the completion cost $\gamma^{P}$, the winning agent $i$ will want to complete the project with the principal if and only if $\beta_{i}-\left(c-k_{i}\right) \geq-t_{i}^{F}$. It is convenient to define the payment

$$
p_{i}\left(k_{i}, k_{-i}\right)=\beta_{i}\left(k_{i}, k_{-i}\right)+t_{i}^{F}\left(k_{i}, k_{-i}\right) .
$$

Then, the agent completes the principal's project if and only if

$$
p_{i} \geq c-k_{i} .
$$

The payment $p_{i}$ can be interpreted as the damage clause stipulated in the contract. To see this, suppose the agent is paid the bonus $b_{i}=\beta_{i}$ not upon project completion but up-front, before and independently of project completion. If the agent fails to complete, it must pay damages to the principal. If $p_{i}$ is the size of the damages paid in case of breach, then the total transfer from the winning agent to the principal in case of breach is $p_{i}-b_{i}=p_{i}-\beta_{i}=t_{i}^{F}$.

By raising the winner's stipulated damage payment $p_{i}$, the principal reduces the probability of the agent breaching; $\min \left\{p_{i}+k_{i}, c^{+}\right\}$is the highest level of the opportunity cost component $c$ at which the project is completed.

Note that if the winning agent completes the project for the principal, his payoff net of the outside option is

$$
\left(\beta_{i}-k_{i}-\gamma^{P}\right)-\left(E[\omega]-E\left[\gamma^{A}\right]-k_{i}\right)=p_{i}-t_{i}^{F}-c
$$

If, on the other hand, the winning agent quits, his payoff net of the outside option is the cost sunk in the principal's project minus the amount charged after failure to complete, $-k_{i}-t_{i}^{F}$. Thus, agent $i$ 's expected payoff net of the outside option payoff from participating in the procurement mechanism when his cost type is $k_{i}$ and he reports $z$, while the other agents report their true types, is: ${ }^{10}$

$$
\begin{aligned}
& U\left(z ; k_{i}\right)=\int_{K_{-i}}\left\{\int_{c^{-}}^{p_{i}\left(z, k_{-i}\right)+k_{i}}\left[p_{i}\left(z, k_{-i}\right)-t_{i}^{F}\left(z, k_{-i}\right)-c\right] f(c) d c \pi_{i}\left(z, k_{-i}\right)\right. \\
& \left.-\int_{p_{i}\left(z, k_{-i}\right)+k_{i}}^{c^{+}}\left[k_{i}+t_{i}^{F}\left(z, k_{-i}\right)\right] f(c) d c \pi_{i}\left(z, k_{-i}\right)-t_{i}^{L}\left(z, k_{-i}\right)\left[1-\pi_{i}\left(z, k_{-i}\right)\right]\right\} g_{-i}\left(k_{-i}\right) d k_{-i}
\end{aligned}
$$

\footnotetext{
${ }^{10}$ To simplify notation, here and in the remainder of the paper we replace $\min \left\{p_{i}+k_{i}, c^{+}\right\}$with $p_{i}+k_{i}$ as the highest opportunity cost $c$ at which the project is completed, exploiting the fact that $f(c)=0$ and $F(c)=1$ for $c>c^{+}$.
} 
Defining

$$
t_{i}\left(k_{i}, k_{-i}\right)=t_{i}^{F}\left(k_{i}, k_{-i}\right) \pi_{i}\left(k_{i}, k_{-i}\right)+t_{i}^{L}\left(k_{i}, k_{-i}\right)\left[1-\pi_{i}\left(k_{i}, k_{-i}\right)\right],
$$

we can rewrite agent $i$ 's expected payoff as:

$$
\begin{aligned}
U\left(z ; k_{i}\right) & =\int_{K_{-i}}\left\{\int_{c^{-}}^{p_{i}\left(z, k_{-i}\right)+k_{i}}\left[p_{i}\left(z, k_{-i}\right)+k_{i}-c\right] f(c) d c \pi_{i}\left(z, k_{-i}\right)\right. \\
& \left.-k_{i} \pi_{i}\left(z, k_{-i}\right)-t_{i}\left(z, k_{-i}\right)\right\} g_{-i}\left(k_{-i}\right) d k_{-i}
\end{aligned}
$$

Given that in equilibrium each agent must report truthfully, $U\left(k_{i}\right)=U\left(k_{i} ; k_{i}\right)$ is type $k_{i}$ of agent $i$ 's net utility gain.

For simplicity, we assume that the principal obtains a benefit $V$ only if the project is completed; the principal obtains zero benefit if the agent breaches the agreement and fails to complete the project. We assume that the benefit $V$ is higher than the expected opportunity cost component $c, V>E[c]$. Thus, the principal's expected payoff from agent $i$ under truthtelling is:

$$
\begin{aligned}
U_{i}^{P} & =\int_{K} \int_{K_{-i}}\left\{\int_{c^{-}}^{p_{i}\left(k_{i}, k_{-i}\right)+k_{i}}\left[V-p_{i}\left(k_{i}, k_{-i}\right)\right] f(c) d c \pi_{i}\left(k_{i}, k_{-i}\right)\right. \\
& \left.+t_{i}\left(k_{i}, k_{-i}\right)\right\} g_{-i}\left(k_{-i}\right) d k_{-i} g\left(k_{i}\right) d k_{i}
\end{aligned}
$$

Using (1), $U_{i}^{P}$ can be rewritten as

$$
\begin{aligned}
U_{i}^{P}= & \int_{K} \int_{K_{-i}}\left\{\int_{c^{-}}^{p_{i}\left(k_{i}, k_{-i}\right)+k_{i}}\left[V-c+k_{i}\right] f(c) d c \pi_{i}\left(k_{i}, k_{-i}\right)\right. \\
& \left.-k_{i} \pi_{i}\left(k_{i}, k_{-i}\right)-U\left(k_{i}\right)\right\} g_{-i}\left(k_{-i}\right) d k_{-i} g\left(k_{i}\right) d k_{i}
\end{aligned}
$$

The principal's problem is to maximize $\sum_{i=1}^{N} U_{i}^{P}$ subject to the constraints that 1) it is an equilibrium for the agents to report their true types; 2) all agents make a non-negative expected payoff net of the outside option, i.e., $U\left(k_{i}\right) \geq 0$ for all types $k_{i}$ that participate in the mechanism; 3) $\sum_{i=1}^{N} \pi_{i}(\cdot) \leq 1$ and $\pi_{i}(\cdot) \geq 0$.

\section{The Full Information Benchmark}

If the cost types $k_{i}$ of all players are known, then the principal can extract all surplus from the agents by setting $U\left(k_{i}\right)=0$. Define

$$
S_{i}^{1}\left(k_{i} ; p_{i}\left(k_{i}, k_{-i}\right)\right)=\int_{c^{-}}^{p_{i}\left(k_{i}, k_{-i}\right)+k_{i}}\left[V-c+k_{i}\right] f(c) d c-k_{i}
$$


as the (first-best) total net surplus, or social value, generated by agent $i$ when $i$ wins the project and his opponents have types $k_{-i}$. The principal chooses $p_{i}$ and $\pi_{i}$ so as to maximize $\sum_{i=1}^{N} S_{i}^{1}\left(k_{i} ; p_{i}\left(k_{i}, k_{-i}\right)\right) \pi_{i}\left(k_{i}, k_{-i}\right)$ for all values of $k_{i}$ and $k_{-i}$.

Differentiating $S_{i}^{1}\left(k_{i} ; p_{i}\left(k_{i}, k_{-i}\right)\right)$ with respect to $p_{i}\left(k_{i}, k_{-i}\right)$ for $p_{i}\left(k_{i}, k_{-i}\right)+k_{i}<c^{+}$ gives:

$$
\frac{\partial S_{i}^{1}(\cdot)}{\partial p_{i}\left(k_{i}, k_{-i}\right)}=\left[V-p_{i}\left(k_{i}, k_{-i}\right)\right] f\left(p_{i}\left(k_{i}, k_{-i}\right)+k_{i}\right)
$$

and hence it is optimal to set $p_{i}\left(k_{i}, k_{-i}\right)=V .{ }^{11}$ For $p_{i}+k_{i} \geq c^{+}, S_{i}^{1}$ does not change with $p_{i}$. Thus, it is an optimal pricing policy to set $p_{i}\left(k_{i}, k_{-i}\right)=V$.

Let

$$
k^{T_{1}}=c^{+}-V
$$

and note that $S_{i}^{1}\left(k_{i} ; p_{i}^{F B}\right)$ is positive for all $k_{i}$ since: 1$)$ it is equal to $V-E[c]>0$ for $\left.k_{i} \geq k^{T_{1}} ; 2\right)$ it is strictly decreasing in $k_{i}$ if $k_{i}<k^{T_{1}}$. All agent types generate a positive surplus. As a result, the principal finds it optimal not to exclude any agent type from participating in the mechanism.

Agents with cost types $k_{i}$ higher than $k^{T_{1}}$ never quit, once they have been selected to complete the project. Furthermore, the principal obtains the same surplus from all of them and hence may as well award the project randomly to one of them if there are no lower types. From now on, when the principal is indifferent about awarding the project to different agents, we will always select the mechanism that uses a fair lottery to determine the winner.

For a given type profile $k_{i}, k_{-i}$, let $k^{\text {min }}=\min _{i \in \mathcal{N}} k_{i}$ and $n^{\text {min }}$ be the number of agents of type $k^{\mathrm{min}}$. If $k^{\mathrm{min}}<k^{T_{1}}$, then it is optimal for the principal to assign the task to one of the agents with the lowest private cost type $k^{\mathrm{min}}$. Such an agent generates the highest total net surplus, since $S_{i}^{1}$ decreases with $k_{i}$ if $k_{i}<k^{T_{1}}$.

The next proposition summarizes the optimal mechanism under complete information.

Proposition 1 Under complete information about the cost types of agents, for all $k_{i}, k_{-i}$, in the optimal procurement mechanism the project is awarded according to the following rule:

$$
\pi_{i}^{F B}\left(k_{i}, k_{-i}\right)=\left\{\begin{array}{lll}
\frac{1}{n^{\min }} & \text { if } & k_{i}=k^{\mathrm{min}} \leq k^{T_{1}}=c^{+}-V \\
\frac{1}{N} & \text { if } & k^{\mathrm{min}}>k^{T_{1}} \\
0 & & \text { otherwise. }
\end{array}\right.
$$

\footnotetext{
${ }^{11} S_{i}^{1}$ increases with $p_{i}$ if $p_{i}<V$ and decreases in $p_{i}$ if $p_{i}>V$.
} 
The agent's information rent is zero; for all $k_{i} \in K$

$$
U\left(k_{i}\right)=0
$$

The optimal mechanism specifies liquidated damages equal to expectation damages: ${ }^{12}$

$$
p_{i}^{F B}\left(k_{i}, k_{-i}\right)=V
$$

and can be implemented by setting a zero participation fee $t_{i}^{L}$ and an up-front payment equal to the project's benefit to the principal minus its social value:

$$
b_{i}^{F B}\left(k_{i}, k_{-i}\right)=V-S_{i}^{1}\left(k_{i} ; V\right)
$$

The formula for $b_{i}^{F B}\left(k_{i}, k_{-i}\right)$ is obtained from (1). By setting $p_{i}=V$, the principal aligns the winning agent's incentives with his own. It is as if the principal sold the project to the agent, who will then quit when it is socially optimal to quit. In addition, the principal sets the up-front payment and participation fee that extract all the surplus from the agents. Indeed, the participation fee $t_{i}^{L}$ can be set equal to zero, so that the losing agents are not charged. ${ }^{13}$

It is important to stress that it is not efficient, and the principal will not want, to always induce the agent to complete the project. As we shall see in the next section, with private information the completion decision will be distorted away from efficiency and the stipulated damages will differ from expectation damages.

Finally, it is useful to distinguish between three cases, depending on the value of the project relative to the completion and private cost types. We say that the project is high value if $V \geq c^{+}-k^{-}$. In this case it is $k^{-} \geq k^{T_{1}}$; agents never quit the project and the project is assigned by a fair lottery. We say that the project is low value if $V \leq c^{+}-k^{+}$. In this case, the project is always awarded to the agent with the lowest private cost type. The winner will quit if the completion cost is higher than $V+k_{i}$, an event that has positive probability. If the project has an intermediate value, $c^{+}-k^{+}<V<c^{+}-k^{-}$, two cases are possible: a) the lowest private cost

\footnotetext{
${ }^{12}$ Since $V$ is the project's benefit, it is also equal to the principal's damages if the project is not completed.

${ }^{13}$ An alternative way to implement the optimal mechanism is to charge all agents a positive participation fee $t_{i}^{L}$; the fee amounts $t_{i}^{L}$ clearly decrease with the number of bidders $N$, as an increase in $N$ decreases the probability of winning the project (and hence making a profit).
} 
type is above the threshold $k^{T_{1}}$ and the project is allocated by lottery and always completed; b) the lowest private cost type is below the threshold $k^{T_{1}}$ and the project is assigned to the agent with the lowest private cost type and completed only if the completion cost turns out to be below $V+k_{i}$.

\section{The Optimal Mechanism under Private Information}

The first question we want to ask is the following. In the presence of private information could the principal induce the agent to make the efficient completion decision? The answer is positive and the reason is simple. The principal could set the stipulated damages to be $p_{i}=V$. Indeed, as we shall see, the principal could also make sure that the agent winning the project is the same as in the case of complete information.

When the cost types are private information, however, agents will be able to obtain information rents. As in the standard principal-agent model, to reduce the information rents, the principal will find it optimal to distort the completion decision of the agent away from the first best, complete information, outcome. What is the direction of the distortion? Will the principal increase or decrease the probability of a quit? Will the principal use a lottery to assign the project more or less often? Will stipulated damages be above or below expectation damages?

The standard approach to solve for an optimal mechanism under incomplete information uses revenue equivalence; that is, it uses the fact that in the standard problem the payments to the agents (and hence the principal's payoff) are determined once one fixes the payoff of the worst-off agent and the probability of winning by each agent. We need to modify this approach here, because in our model the payment to the project winner determines whether the winner quits, and also affects the principal's payoff through that channel. What will be true in our model is that once one fixes the payoff to the worst-off agent, the transfer $t_{i}$ is determined by the probabilities of winning $\pi_{i}$ and the stipulated damages $p_{i}$.

Consider equation (1); the incentive compatibility constraint and an envelope theorem argument yield:

$$
\frac{d U\left(k_{i}\right)}{d k_{i}}=\left.\frac{\partial U\left(z, k_{i}\right)}{\partial k_{i}}\right|_{z=k_{i}}=-\int_{K_{-i}}\left[1-F\left(p_{i}\left(k_{i}, k_{-i}\right)+k_{i}\right)\right] \pi_{i}\left(k_{i}, k_{-i}\right) g_{-i}\left(k_{-i}\right) d k_{-i}
$$

Equation (2) is a first order condition on agent $i$ 's maximization problem. We will proceed by ignoring the second order condition; Lemma 1 in the appendix shows that 
it is satisfied by the solution of the principal's problem.

Since by (2) agent $i$ 's equilibrium expected payoff is decreasing in $k_{i}$, the individual rationality, or participation, constraint is satisfied as long as it is satisfied for the highest type. Then, we can write the individual rationality constraint as follows:

$$
U\left(k^{+}\right) \geq 0
$$

Using (2) and integrating by parts we obtain:

$$
\begin{aligned}
& \int_{k^{-}}^{k^{+}} U\left(k_{i}\right) g\left(k_{i}\right) d k_{i} \\
& =U\left(k^{+}\right)+\int_{k^{-}}^{k^{+}} \int_{k_{i}}^{k^{+}} \int_{K_{-i}}\left[1-F\left(p_{i}\left(k, k_{-i}\right)+k\right)\right] \pi_{i}\left(k, k_{-i}\right) g_{-i}\left(k_{-i}\right) d k_{-i} d k g\left(k_{i}\right) d k_{i} \\
& =U\left(k^{+}\right)+\int_{k^{-}}^{k^{+}} \int_{K_{-i}}\left[1-F\left(p_{i}\left(k_{i}, k_{-i}\right)+k_{i}\right)\right] \pi_{i}\left(k_{i}, k_{-i}\right) g_{-i}\left(k_{-i}\right) d k_{-i} G\left(k_{i}\right) d k_{i} .
\end{aligned}
$$

Note that while the principal could set $p_{i}=V$ and thus induce the agent to make the same completion decision as under complete information, by raising $p_{i}$ above $V$ the principal is able to reduce the agent's information rent.

The principal's total payoff can be written as

$$
\begin{aligned}
U^{P} & =-\sum_{i=1}^{N} U\left(k^{+}\right)+\sum_{i=1}^{N} \int_{K_{-i}} \int_{k^{-}}^{k^{+}}\left\{\int_{c^{-}}^{p_{i}\left(k_{i}, k_{-i}\right)+k_{i}}\left[V+k_{i}+\frac{G\left(k_{i}\right)}{g\left(k_{i}\right)}-c\right] f(c) d c\right. \\
& \left.-k_{i}-\frac{G\left(k_{i}\right)}{g\left(k_{i}\right)}\right\} \pi_{i}\left(k_{i}, k_{-i}\right) g\left(k_{i}\right) d k_{i} g_{-i}\left(k_{-i}\right) d k_{-i}
\end{aligned}
$$

The principal's program is to maximize $U^{P}$ subject to the constraint that $\pi_{i}$ is a probability and $U\left(k^{+}\right) \geq 0$. It is immediate that the principal should set $U\left(k^{+}\right)=0$. The agent with the highest private cost type will get no information rent. Indeed, by (2) no agent that completes the project with probability one (i.e., such that $p_{i}+k_{i} \geq c^{+}$) obtains an information rent.

Let

$$
S_{i}^{2}\left(k_{i} ; p_{i}\left(k_{i}, k_{-i}\right)\right)=\int_{c^{-}}^{p_{i}\left(k_{i}, k_{-i}\right)+k_{i}}\left[V+k_{i}+\frac{G\left(k_{i}\right)}{g\left(k_{i}\right)}-c\right] f(c) d c-k_{i}-\frac{G\left(k_{i}\right)}{g\left(k_{i}\right)}
$$

be the (second-best) net total surplus the principal would obtain from assigning the project to agent $i$.

First note that $S_{i}^{2}$ does not depend on $p_{i}\left(k_{i}, k_{-i}\right)$ if $p_{i}\left(k_{i}, k_{-i}\right)+k_{i}>c^{+}$. On the other hand, when $p_{i}\left(k_{i}, k_{-i}\right)+k_{i}<c^{+}$, differentiating $S_{i}^{2}$ with respect to $p_{i}\left(k_{i}, k_{-i}\right)$ 
yields

$$
\frac{\partial S_{i}^{2}(\cdot)}{\partial p_{i}\left(k_{i}, k_{-i}\right)}=\left[V+\frac{G\left(k_{i}\right)}{g\left(k_{i}\right)}-p_{i}\left(k_{i}, k_{-i}\right)\right] f\left(p_{i}\left(k_{i}, k_{-i}\right)+k_{i}\right)
$$

Define $k^{T_{2}}$ as the (unique) solution to ${ }^{14}$

$$
V+\frac{G\left(k^{T_{2}}\right)}{g\left(k^{T_{2}}\right)}+k^{T_{2}}=c^{+} .
$$

Note that $k^{T_{2}}$ plays the same role played by $k^{T_{1}}$ under complete information. It follows that it is optimal for the principal to set

$$
p_{i}^{S B}\left(k_{i}, k_{-i}\right)=\left\{\begin{array}{lll}
V+\frac{G\left(k_{i}\right)}{g\left(k_{i}\right)} & \text { if } \quad k_{i} \leq k^{T_{2}} \\
V+\frac{G\left(k^{T_{2}}\right)}{g\left(k^{T_{2}}\right)} & \text { if } \quad k_{i}>k^{T_{2}}
\end{array}\right.
$$

Now observe that $S_{i}^{2}\left(k_{i} ; p_{i}^{S B}\left(k_{i}, k_{-i}\right)\right)$ is positive for all $k_{i}$ since: 1$)$ it is equal to $V-E[c]>0$ for $\left.k_{i} \geq k^{T_{2}} ; 2\right)$ it is strictly decreasing in $k_{i}$ if $k_{i}<k^{T_{2}}$. It follows that, as in the case of complete information, the principal does not want to exclude any agent type from participating in the mechanism.

In the optimal mechanism agent types with cost higher than $k^{T_{2}}$ never quit. Note also that the principal obtains the same surplus from all types in the interval $\left[k^{T_{2}}, k^{+}\right]$ and hence will assign the project randomly to one of them if there are no lower types. On the other hand, if $k^{\text {min }}<k^{T_{2}}$, then it is optimal for the principal to award the job to one of the agents with the lowest cost type $k_{i}$; since $S_{i}^{2}$ decreases with $k_{i}$, such an agent generates the highest total net surplus to the principal.

The next proposition summarizes the optimal mechanism under incomplete information.

Proposition 2 In the optimal procurement mechanism under incomplete information about the cost types of agents, for all $k_{i}, k_{-i}$, the project is awarded according to the following rule:

$$
\pi_{i}^{S B}\left(k_{i}, k_{-i}\right)=\left\{\begin{array}{ccc}
\frac{1}{n^{\min }} & \text { if } & k_{i}=k^{\min } \leq k^{T_{2}} \\
\frac{1}{N} & \text { if } & k^{\mathrm{min}}>k^{T_{2}} \\
0 & & \text { otherwise }
\end{array}\right.
$$

\footnotetext{
${ }^{14}$ For values of $k^{T_{2}}<k^{-}$define $\frac{G\left(k^{T_{2}}\right)}{g\left(k^{T_{2}}\right)}=0$. For values of $k^{T_{2}}>k^{+}$define $\frac{G\left(k^{T_{2}}\right)}{g\left(k^{T_{2}}\right)}=\frac{G\left(k^{+}\right)}{g\left(k^{+}\right)}$.
} 
where $k^{T_{2}}$ is the solution to

$$
V+\frac{G\left(k^{T_{2}}\right)}{g\left(k^{T_{2}}\right)}+k^{T_{2}}=c^{+}
$$

Agents with cost types above $k^{T_{2}}$ earn zero information rent; for all $k_{i} \geq k^{T_{2}}$

$$
U\left(k_{i}\right)=0 .
$$

Cost types below $k^{T_{2}}$ obtain a positive information rent; $k_{i}<k^{T_{2}}$ implies $U\left(k_{i}\right)>0$. The optimal mechanism specifies liquidated damages equal to:

$$
p_{i}^{S B}\left(k_{i}, k_{-i}\right)= \begin{cases}V+\frac{G\left(k_{i}\right)}{g\left(k_{i}\right)} & \text { if } \quad k_{i} \leq k^{T_{2}} \\ V+\frac{G\left(k^{T_{2}}\right)}{g\left(k^{T_{2}}\right)} & \text { if } \quad k_{i}>k^{T_{2}}\end{cases}
$$

and can be implemented by setting a zero participation fee $t_{i}^{L}$ and an up-front payment equal to:

$$
b_{i}^{S B}\left(k_{i}, k_{-i}\right)= \begin{cases}V-S_{i}^{2}\left(k_{i} ; V+\frac{G\left(k_{i}\right)}{g\left(k_{i}\right)}\right)+\frac{U\left(k_{i}\right)}{\left[1-G\left(k_{i}\right)\right]^{N-1}} & \text { if } \quad k_{i} \leq k^{T_{2}} \\ V-S_{i}^{2}\left(k^{T_{2}} ; V+\frac{G\left(k^{T_{2}}\right)}{g\left(k^{T_{2}}\right)}\right) & \text { if } \quad k_{i}>k^{T_{2}}\end{cases}
$$

The formula for $b_{i}^{S B}\left(k_{i}, k_{-i}\right)$ is obtained from (1), the formula for $p_{i}^{S B}\left(k_{i}, k_{-i}\right)$ and the facts that $U\left(k_{i}\right)=0$ for $k_{i}>k^{T_{2}}$ while the winning probability of type $k_{i} \leq k^{T_{2}}$ equals the probability that all other types are above $k_{i}$ :

$$
\int_{K_{-i}} \pi_{i}\left(k_{i}, k_{-i}\right) g_{-i}\left(k_{-i}\right) d k_{-i}=\left[1-G\left(k_{i}\right)\right]^{N-1} .
$$

The next proposition is an immediate consequence of $G\left(k_{i}\right)>0$ for all $k_{i}>k^{-}$and $k^{T_{2}}<k^{T_{1}}$.

Proposition 3 Under incomplete information: (1) Stipulated damages $p_{i}^{S B}$ are higher than expectation damages $V$, the first best level of damages, for all except the agent with the lowest private cost type $k^{-}$; hence the project is completed even for realizations of the opportunity cost component $c$ when it would be socially efficient to abandon it. (2) The region of types for which the project is assigned by a fair lottery is larger than under complete information. 
In the optimal mechanism under incomplete information, stipulated damages are punitive; that is, they are higher than the principal's benefit of completing the project $V$. As a result, there are realizations of the opportunity cost component $c$ above $V+k_{i}$ under which the winning agent completes a project that would be efficient to abandon. Note that there is no distortion at the bottom; the liquidated damages of type $k^{-}$are set at $V$.

Every type $k_{i}<k^{T_{2}}$ earns a positive information rent. The principal chooses higher stipulated damages than in the case of complete information in order to reduce the agents' information rents. Interestingly, the principal also expands the region of types under which the project is assigned by lottery. This is also in order to reduce the agents' information rents; indeed, when the project is assigned by a lottery agents obtain no rents. Thus, for some realizations of the type profile a lottery is used and the project is always completed, when it would be socially efficient to award the project to the agent with the lowest private cost type and have it abandoned if the completion cost turns out to be high.

Finally, note that the high value region for which $k^{-} \geq k^{T_{2}}$ and the winning agent never quits the project is the same as under complete information: $V \geq c^{+}-k^{-}$. On the other hand, the low value region for which the project is always awarded to the agent with the lowest private cost type shrinks to $V \leq c^{+}-k^{+}-1 / g\left(k^{+}\right)$, while the intermediate value region expands to $c^{+}-k^{+}-1 / g\left(k^{+}\right)<V<c^{+}-k^{-}$. As we already observed, within the intermediate region, the subregion for which the project is assigned by lottery expands.

\section{Auctions}

One way to interpret the optimal mechanism is as a complex auction in which agents bid over both the up-front bonus and damages and the principal uses a (complex) scoring rule to decide the winner. A natural question addressed in this section is: Are there simple auctions that, at least in some circumstances, implement the optimal mechanism?

The principal could use many different simple auctions formats to determine the project winner. Apart from the standard difference between first and second-price auctions, when the agents may breach the contract it is important to specify the terms over which agents bid. This is because, unlike in standard auctions, the winning bid 
determines both the winner's compensation and when the project will be completed. We look at two formats; in both of them losers' transfers are zero, $t^{L}=0$. In the first format, the bonus auction, the principal fixes the total amount $t^{F}$ to be paid by the winner that fails to complete the project and asks the agents to bid over the bonus $\beta$ the winner gets upon completion. In the second format, the up-frontpayment auction, the principal set the damages $p$ to be paid by the winner in case of breach and let the agents bid over the up-front payment $b$ they receive upon winning. For simplicity, under both formats we look at a second-price auction, in which the contract is awarded to the bidder who has submitted the lowest bid, while the bonus or up-front payment are equal to the second lowest bid. We restrict attention to symmetric Bayesian equilibria.

Proposition 4 The equilibrium bid in a second-price, bonus auction is the solution to

$$
\beta\left(k_{i} ; t\right)=E\left[c \mid c<\beta\left(k_{i} ; t\right)+t+k_{i}\right]+\left(k_{i}+t\right) \frac{1-F\left(\beta\left(k_{i} ; t\right)+t+k_{i}\right)}{F\left(\beta\left(k_{i} ; t\right)+t+k_{i}\right)}
$$

The equilibrium bid in a second-price, up-front-payment auction is

$$
b\left(k_{i} ; p\right)=\int_{c^{-}}^{p+k_{i}} c f(c) d c+\int_{p+k_{i}}^{c^{+}}\left[k_{i}+p\right] f(c) d c
$$

Proof See the Appendix.

To understand the formulas for the bidding functions of the second-price bonus and up-front-payment auctions, recall that in a standard second-price procurement auction the equilibrium bid is the expected cost of the bidder. Thus, if the price were equal to the winner's bid (i.e., if the winner's bid were in a tie with the price-setter's bid), the winner would make zero profit. Proposition 4 shows that when contract breach is possible, the winner would also make zero expected profit if the bonus, or the up-front-payment, were equal to his bid.

In discussing whether auctions can implement the optimal mechanism, it is useful to start from the high value case: $V \geq c^{+}-k^{-}$. In this case, by setting $p=V$ the principal can make sure that the second-price, up-front-payment, auction implements the optimal mechanism. The equilibrium bid is $b\left(k_{i} ; p\right)=E[c]$ and the outcome is the first best outcome; the project is always completed. By setting $t=V-E[c]$, the second-price, bonus auction also implements the optimal mechanism in the high value case. 
On the other hand, in the low value and in the intermediate value regions when $V<c^{+}-k^{-}$, the two auctions formats cannot implement the optimal mechanism. Because the bidding function for the bonus auction is only implicitly defined by (3), it is easier to work with the up-front-payment auction. The next proposition computes the optimal value of the liquidated damages clause $p$, the value that maximizes the principal's expected payoff. Let $k^{(1)}$ be the lowest cost type and $k^{(2)}$ be the second lowest cost type among the $N$ agents.

Proposition 5 The optimal damage clause in the second-price, up-front-payment auction is the solution of

$$
p=V+\frac{E\left[F\left(p+k^{(2)}\right)\right]-E\left[F\left(p+k^{(1)}\right)\right]}{E\left[f\left(p+k^{(1)}\right)\right]} .
$$

The optimal liquidated damages clause $p$ is greater than the expectation damages $V$ as long as $V+k^{-}<c^{+}$. If $V+k^{-} \geq c^{+}$then $p=V$.

Proof See the Appendix.

In the up-front-payment auction that maximizes the principal's payoff, liquidated damages are set above expectation damages except for the case of a high value project, when damages equal expectation damages. This is similar to what happens in the optimal mechanism, but in the optimal mechanism liquidated damages are an increasing function of the winning agent's cost type, while in the up-front-payment auction they are a constant.

It is also important to note that as the number of bidders grows large, the outcome of the up-front-payment auction approaches the outcome of the optimal mechanism. This is because, as the number of agents grows large, the lowest cost and second lowest cost types approach $k^{-}$and hence the liquidated damage clauses in the optimal mechanism and in the up-front-payment auction approach the expectation damages amount $V$.

\section{Conclusions}

The main lesson of this paper is that when the efficiency of breaching a procurement contract is private information of the agent, the procurer will want to use a punitive damage clause that locks in the contractor in order to reduce his information rent. 
Breach is efficient when it relieves the contractor from unusually high completion costs discovered after the contract has been signed, or when a new and more valuable opportunity arises that the contractor can only take up after abandoning the current project. In such circumstances, the court's refusal to recognize the validity of punitive damage clauses, by limiting the principal's ability to extract rent from the agent, may be viewed as efficiency enhancing. At the same time, when the procurer is a government agency, a constraint on the amount of admissible damages moves surplus from the public at large to the private contractor. It is not clear that the courts' stance is justified in such a case.

Another lesson of the paper is that the optimal bidding procedure is complex, in essence requiring agents to bid both on price and the damage clause, and using a scoring rule which is not simple to describe. However, with a large number of bidders, a second-price auction that sets the liquidated damage clause to expectation damages and asks agents to bid on the up-front payment for the project approximates the optimal mechanism.

\section{Appendix}

In this appendix, first we prove a lemma that deals with the second order condition of the agents' reporting problem. Then we provide a proof of Propositions 4 and 5.

Lemma 1 Consider the mechanism described by the functions $p_{i}\left(k_{i}, k_{-i}\right), t_{i}\left(k_{i}, k_{-i}\right)$, $\pi_{i}\left(k_{i}, k_{-i}\right)$ for all $i$. Suppose that $(a) p_{i}\left(k_{i}, k_{-i}\right)=p_{i}\left(k_{i}\right)$ (i.e., $p_{i}$ does not depend on the types $\left.k_{-i}\right) ;(b) p_{i}\left(k_{i}\right)$ is increasing in $k_{i}$ and differentiable; $(c) \Pi_{i}\left(k_{i}\right)=$

$\int_{K_{-i}} \pi_{i}\left(k_{i}, k_{-i}\right) g_{-i}\left(k_{-i}\right) d k_{-i}$ exists and is (weakly) decreasing in $k_{i}$. If this mechanism satisfies the first order condition of the agent's reporting problem, then it also satisfies the second order condition and hence it is incentive compatible.

Proof Consider the first order condition of agent $i$ reporting problem:

$$
\left.\frac{\partial U\left(z, k_{i}\right)}{\partial z}\right|_{z=k_{i}}=0
$$

Differentiating it totally yields

$$
\left.\frac{\partial^{2} U\left(z, k_{i}\right)}{\partial z \partial k_{i}}\right|_{z=k_{i}}+\left.\frac{\partial^{2} U\left(z, k_{i}\right)}{\partial z^{2}}\right|_{z=k_{i}}=0 .
$$


Since

$$
\frac{\partial U\left(z, k_{i}\right)}{\partial k_{i}}=-\int_{K_{-i}}\left[1-F\left(p_{i}\left(z, k_{-i}\right)+k_{i}\right)\right] \pi_{i}\left(z, k_{-i}\right) g_{-i}\left(k_{-i}\right) d k_{-i},
$$

under the hypotheses of the lemma, we can write the second order condition as:

$$
\begin{gathered}
-\left.\frac{\partial^{2} U\left(z, k_{i}\right)}{\partial z^{2}}\right|_{z=k_{i}}=\left.\frac{\partial^{2} U\left(z, k_{i}\right)}{\partial z \partial k_{i}}\right|_{z=k_{i}} \\
=-\left[1-F\left(p_{i}\left(k_{i}\right)+k_{i}\right)\right] \frac{d \Pi_{i}\left(k_{i}\right)}{d k_{i}}+f\left(p_{i}\left(k_{i}\right)+k_{i}\right) \frac{d p_{i}\left(k_{i}\right)}{d k_{i}} \Pi_{i}\left(k_{i}\right) \geq 0 .
\end{gathered}
$$

Proof of Proposition 4 Consider first a second-price, bonus auction. Let $\beta\left(k_{i}\right)$ be the bidding function (for notational simplicity we drop the dependence on $t$ ) and assume provisionally that it is strictly increasing everywhere. Let $Q(k)=[1-G(k)]$. We can write bidder $i$ 's problem of determining the optimal value of his bid $b$ as:

$\max _{b} \int_{\beta^{-1}(b)}^{k^{+}}\left\{\int_{c^{-}}^{\beta(k)+k_{i}+t}\left[\beta(k)+k_{i}+t-c\right] f(c) d c-\left(k_{i}+t\right)\right\}(N-1) g(k) Q(k)^{N-2} d k$.

The first order condition is

$-\frac{d \beta^{-1}(b)}{d b}\left\{\int_{c^{-}}^{b+k_{i}+t}\left[b+k_{i}+t-c\right] f(c) d c-\left(k_{i}+t\right)\right\}(N-1) g\left(\beta^{-1}(b)\right) Q\left(\beta^{-1}(b)\right)^{N-2}=0$,

which yields, using the Nash equilibrium condition $b=\beta\left(k_{i}\right)$,

$$
\int_{c^{-}}^{\beta\left(k_{i}\right)+k_{i}+t}\left[\beta\left(k_{i}\right)+k_{i}+t-c\right] f(c) d c-k_{i}-t=0
$$

or

$$
\beta\left(k_{i}\right)=E\left[c \mid c<\beta\left(k_{i}\right)+k_{i}+t\right]+\left(k_{i}+t\right) \frac{1-F\left(\beta\left(k_{i}\right)+k_{i}+t\right)}{F\left(\beta\left(k_{i}\right)+k_{i}+t\right)} .
$$

It is immediate to see that the second order condition is satisfied and that Equation (6) defines the equilibrium bidding function, as long as $\beta\left(k_{i}\right)$ is strictly increasing. To see that $\beta\left(k_{i}\right)$ is increasing, note that if we differentiate $(5)$ with respect to $k_{i}$ we obtain

$$
\int_{c^{-}}^{\beta\left(k_{i}\right)+k_{i}+t}\left[\beta^{\prime}\left(k_{i}\right)+1\right] f(c) d c-1=0
$$

and hence

$$
\beta^{\prime}\left(k_{i}\right)=\frac{1-F\left(\beta\left(k_{i}\right)+k_{i}+t\right)}{F\left(\beta\left(k_{i}\right)+k_{i}+t\right)}>0 \quad \text { for } \beta\left(k_{i}\right)+k_{i}+t<c^{+} .
$$


Using (6), we see that $\beta\left(k_{i}\right)+k_{i}+t<c^{+}$for types $k_{i}$ such that $k_{i}<c^{+}-E[c]-t$. Thus, we have shown that if $k_{i}<c^{+}-E[c]-t$ then bidder $k_{i}$ will bid according to $\beta\left(k_{i} ; t\right)$.

Now suppose $\beta\left(k_{i}\right)+k_{i}+t \geq c^{+}$or, equivalently, $k_{i} \geq c^{+}-E[c]-t$. When winning, bidder $k_{i}$ will complete the contract with certainty and therefore must bid no less than the expected cost; furthermore, he will certainly lose the auction if he asks for more than the expected cost. It follows that the equilibrium bid is $E[c]$. Thus, since $\beta\left(k_{i}\right)=E[c]$ for $k_{i} \geq c^{+}-E[c]$, bidding according to $\beta\left(k_{i}\right)$ is also an equilibrium for these types.

Now consider a second-price, up-front-payment auction. Let $p$ be the damages and $b\left(k_{i}\right)$ be the bidding function (for notational simplicity we drop the dependence on $p$ ) and assume provisionally that it is strictly increasing everywhere. We can write bidder $i$ 's problem of determining the optimal value of his bid $\widetilde{b}$ (the up-front payment) as:

$$
\max _{\widetilde{b}} \int_{b^{-1}(\widetilde{b})}^{k^{+}}\left\{b(k)-\int_{c^{-}}^{p+k_{i}} c f(c) d c-\int_{p+k_{i}}^{c^{+}}\left[k_{i}+p\right] f(c) d c\right\}(N-1) g(k) Q(k)^{N-2} d k .
$$

The first order condition is

$$
-\frac{d b^{-1}(\widetilde{b})}{\widetilde{d b}}\left\{\widetilde{b}-\int_{c^{-}}^{p+k_{i}} c f(c) d c-\int_{p+k_{i}}^{c^{+}}\left[k_{i}+p\right] f(c) d c\right\}(N-1) g\left(b^{-1}(\widetilde{b})\right) Q\left(b^{-1}(\widetilde{b})\right)^{N-2}=0,
$$

which yields, using the Nash equilibrium condition $\widetilde{b}=b\left(k_{i} ; p\right)$ :

$$
b\left(k_{i} ; p\right)=\int_{c^{-}}^{p+k_{i}} c f(c) d c+\int_{p+k_{i}}^{c^{+}}\left[k_{i}+p\right] f(c) d c .
$$

It remains to check that $b$ is increasing in $k_{i}$. This follows immediately:

$$
\frac{\partial b\left(k_{i} ; p\right)}{\partial k_{i}}=1-F\left(p+k_{i}\right) .
$$

Note that the fact that $b$ is increasing also implies that the second order condition holds.

Proof of Proposition 5 Observe from (4) that

$$
\frac{\partial b\left(k_{i} ; p\right)}{\partial p}=1-F\left(p+k_{i}\right)
$$


Let $k^{(1)}$ be the lowest cost type, $k^{(2)}$ be the second lowest cost type, and $g_{k^{(1)}, k^{(2)}}(x, y)$ be their joint density. The principal chooses $p$ to maximize

$$
\int_{k^{-}}^{k^{+}} \int_{k^{-}}^{k^{+}}\left\{\int_{c^{-}}^{p+x} V f(c) d c+\int_{p+x}^{c^{+}} p f(c) d c-b(y ; p)\right\} g_{k^{(1)}, k^{(2)}}(x, y) d x d y
$$

which yields the first order condition

$\int_{k^{-}}^{k^{+}} \int_{k^{-}}^{k^{+}}\{[V-p] f(p+x)+[1-F(p+x)]-[1-F(p+y)]\} g_{k^{(1)}, k^{(2)}}(x, y) d x d y=0$

or

$[V-p] \int_{k^{-}}^{k^{+}} \int_{k^{-}}^{k^{+}} f(p+x) g_{k^{(1)}, k^{(2)}}(x, y) d x d y-\int_{k^{-}}^{k^{+}} \int_{k^{-}}^{k^{+}}[F(p+x)-F(p+y)] g_{k^{(1)}, k^{(2)}}(x, y) d x d y=0$

from which we obtain

$$
p=V+\frac{E\left[F\left(p+k^{(2)}\right)\right]-E\left[F\left(p+k^{(1)}\right)\right]}{E\left[f\left(p+k^{(1)}\right)\right]} .
$$

Since $k^{(1)}<k^{(2)}$ it is immediate to see that the optimal damage clause is $p>V$ as long as $V+k^{-}<c^{+}$. If $V+k^{-} \geq c^{+}$then $F\left(V+k_{1}\right)=F\left(V+k_{2}\right)=1$ for all $k_{1}, k_{2}$ and $p=V$.

\section{Acknowledgments}

Financial support from Fondazione Cariparo is gratefully acknowledged.

\section{References}

Albano, G., Bianchi, M., Spagnolo, G.: Bid Average Methods in Procurement. Riv Polit Econ 1-2, 41-62 (2006)

Asker, J.: Bidding up, Buying out and Cooling-off: An Examination of Auctions with Withdrawal Rights. Econ Theory 16, 585-611 (2000)

Board, S.: Bidding into the Red: A Model of Post-Auction Bankruptcy. J Financ 62, 2695-2723 (2007)

Burguet, R., Ganuza, J.J., Hauk, E.: Limited Liability and Mechanism Design in Procurement. Game Econ Behav 76, 1, 15-25 (2012) 
Chung, T.Y.: On the Social Optimality of Liquidated Damage Clauses: An Economic Analysis. J Law Econ Organ 8, 280-305 (1992)

Decarolis, F.: When the Highest Bidder Loses the Auction: Theory and Evidence from Public Procurement. Unpublished (2011)

Eidlin, A.S., Reichelstein, S.: Holdups, Standard Breach Remedies and Optimal Investment. Am Econ Rev 86, 478-501 (1996)

Edlin, A.S., Schwartz, A.: Optimal Penalties in Contracts. Chicago-Kent Law Rev (2003), available at: http://works.bepress.com/aaron_edlin/30

Ganaway, N.B.: Construction Business Management: a Guide to Contracting for Business Success. Butterworth-Heinemann, Oxford (2006)

Milgrom. P.: Putting Auction Theory to Work. Cambridge University Press, Cambridge (2004)

Parlane, S.: Procurement Contracts under Limited Liability. Econ Soc Rev 34, 1-21 (2003)

Postl, P.: Efficiency versus optimality in procurement. Econ Theory (2012). doi: $10.1007 / \mathrm{s} 00199-012-0699-\mathrm{x}$

Ramchurn, S.D., Mezzetti,C., Giovannucci, A., Rodriguez-Aguilar, J.A., Dash, R.K., Jennings, N.J.: Trust-Based Mechanisms for Robust and Efficient Task Allocation in the Presence of Execution Uncertainty. J Artif Intell Res 35, 119-159 (2009)

Rezende, L.: Biased procurement auctions. Econ Theory 38, 169-185 (2009)

Rhodes-Kropf, M., Viswanathan, S.: Financing Auction Bids. Rand J Econ 36, 4, 789-815 (2005)

Spulber, D.F.: Auctions and Contract Enforcement. J Law Econ Organ 6, 2, 325-344 (1990)

Stole, L.A.: The Economics of Liquidated Damage Clauses in Contractual Environments with Private Information. J Law Econ Organ 8, 582-606 (1992)

Von Ungern-Sternberg, T.: Swiss Auctions. Economica 58, 341-57 (1991)

Waehrer, K.: A Model of Auction Contracts with Liquidated Damages. J Econ Theory 67, 2, 531-555 (1995)

Wan, Z., Beil, D. R.: RFQ Auctions with Supplier Qualification Screening. Oper Res 57(4), 934-949 (2009)

Zheng, C.Z.: High Bids and Broke Winners. J Econ Theory 100(1),129-171 (2001) 
Zheng, C.Z.: The Default-Prone U.S. Toxic Asset Auction Plan. B.E. J Econ Anal \& Policy 38(1), 41-72 (2009) 


\section{University Library}

\section{- M M I N E R VA A gateway to Melbourne's research publications}

Minerva Access is the Institutional Repository of The University of Melbourne

Author/s:

Chillemi, O;Mezzetti, C

Title:

Optimal procurement mechanisms: bidding on price and damages for breach

Date:

2014-02-01

Citation:

Chillemi, O. \& Mezzetti, C. (2014). Optimal procurement mechanisms: bidding on price and damages for breach. ECONOMIC THEORY, 55 (2), pp.335-355. https://doi.org/10.1007/ s00199-013-0751-5.

Persistent Link:

http://hdl.handle.net/11343/282833 